\title{
PEMANFAATAN SISTEM INFORMASI GEOGRAFIS UNTUK PEMETAAN SEKOLAH SMA/SMK DI KOTA MALANG BERBASIS WEB
}

\author{
Mohamad Fat'al Ghozali, Sentot Achmadi, Hani Zulfia Zahro' \\ Program Studi Teknik Informatika S1, Fakultas Teknologi Industri \\ Institut Teknologi Nasional Malang, Jalan Raya Karanglo km 2 Malang, Indonesia \\ aalg560@gmail.com
}

\begin{abstract}
ABSTRAK
Pengembangan sistem informasi geografis memberikan kemudahan para calon siswa baru dalam mencari informasi tentang tempat pendidikan SMA dan SMK yang ada di Kota Malang dan membatu Diknas Kota Malang untuk menganalisis penerimaan siswa baru dengan menambahkan kuota jumlah siswa luar kota dan kuota siswa dalam zonasi. Perlu dibuat sebuah aplikasi pemetaan sekolah untuk memudahkan mencari tempat pendidikan SMA dan SMK di Kota Malang.

Penelitian ini mengembangkan sistem informasi geografis pemetaan sekolah SMA/SMK di Kota Malang untuk membantu siswa mencari pendidikan SMA/SMK Negeri terdapat 10 SMA negeri dan 13 SMK Negeri di Kota Malang. Pada sistem ini dibuat menggunakan ArcGis 10.7 dan menggunakan Qgis 2.18 dengan adanya teknologi informasi ini kedepannya akan lebih mempermudah untuk mendapatkan informasi sekolah SMA dan SMK Negeri di Kota Malang dengan informasi yang lebih detail dari tiap-tiap Sekolah.

Setelah melakukan pengembangan sistem informasi geografis hasil uji yang di dapat dari hasil uji dari penelitian yang telah dikembangkan yaitu Sistem Informasi Geografis untuk Pemetaan Sekolah SMA/SMK di Kota Malang berbasis website bahwa hasil dari program yang telah dibuat memiliki hasil yang baik, dibuktikan dari hasil pengujian fungsional sistem dengan akses sebagai user, admin sesuai dengan fungsinya pada browser. Semua fungsi dari sistem berjalan sesuai dengan yang di inginkan.
\end{abstract}

Kata Kunci: Sistem Informasi Geografis, SMA dan SMK Negeri, Kota Malang, Pemetaan

\section{PENDAHULUAN}

\subsection{Latar Belakang}

Wilayah Kota Malang merupakan salah satu Kota dengan julukan Kota Pendidikan di Jawa Timur, Julukan ini muncul lantaran banyaknya jumlah kampus dan sekolah yang ada di Kota Malang. Terdapat setidaknya lebih dari 80 Perguruan Tinggi yang tersebar di wilayah Kota Malang. Di Kota Malang terdapat sekolah SMK dan SMA baik Negeri maupun Swasta. Hal ini menarik minat calon siswa dengan menjadikan Kota Malang sebagai destinasi bagi para calon pelajar menengah untuk menempuh pendidikan. Dengan menggunakan system informasi geografiis yang dapat membantu memberikan informasi-informasi yang diinginkan dan lebih banyak lagi informasi yang diberikan.

Untuk saat ini calon siswa ada yang kesulitan mencari sekolah SMA atau SMK negeri di Kota Malang khususnya calon siswa yang berasal dari luar Kota malang yang ingin sekolah di Malang masih tidak mengetahui lokasi sekolah-sekolah di Kota Malang. Penelitian ini dilakukan untuk mengembangkan teknologi informasi yang dapat membantu Diknas Pendidikan Kota Malang. Dengan adanya teknologi ini kedepannya dapat membantu Diknas Pendidikan memudahkan untuk mengetahui lokasi sekolah SMA dan SMK negeri di Kota Malang dan juga Diknas Pendidikan dapat menganalisis jumlah penerimaan siswa baru dengan jumlah kelas yang dimiliki oleh setiap sekolah atau juga dapat menambahkan kuota jumlah siswa luar kota atau bisa juga menambahkan kuota siswa dalam zonasi. Dari penelitian ini dapat membuat system informasi geografis yang bermanfaat sebagai sumber refrensi SMA dan SMK negeri dalam pengolahan Sekolah.

Dari permasalahan diatas maka akan dapat dibangun sebuah sistem informasi geografis, perlu dibuat sebuah aplikasi pemetaan sekolah untuk memudahkan mendapatkan informasi dan mencari tempat pendidikan SMA dan SMK di Kota Malang. Dengan pengelompokan data informasi meliputi data Nama Sekolah, akreditasi sekolah, jurusan sekolah, website sekolah serta kuota Penerimaan Peserta Didik Baru (PPDB) sekolah yang dapat membantu calon siswa baru untuk mandapatkan informasi dan menentukan sekolah yang diinginkan.

\subsection{Rumusan Masalah}

Dari latar belakang tersebut, maka dapat dirumuskan permasalahan sebagai berikut:

1. Bagaimana membangun sistem informasi geografis pemetaan sekolah SMA/SMK di Kota Malang.

2. Bagaimana menyediakan aplikasi system informasi geografis yang dapat memberikan informasi yang berguna untuk mengetahui lokasi sekolah SMA/SMK di Kota Malang. 


\subsection{Tujuan}

Tujuan dari penelitian ini sebagai berikut:

1. Merancang dan membangun sistem informasi geografis pemetaan sekolah.

2. Menyediakan aplikasi sistem informasi geografis yang dapat memberikan informasi berguna untuk mengetahui informasi dan lokasi sekolah SMA/SMK Kota Malang.

\subsection{Batasan Masalah}

Berdasarkan pembuatan sistem informasi geografis ini agar tidak melebar terlalu jauh maka terdapat beberapa batasan dalam pembuatan yaitu sebagai berikut:

1. Aplikasi ini hanya berbasis Web

2. Pembuatan peta digital dibuat menggunakan software Arcgis

3. Data yang digunakan dalam penelitian ini adalah data dari website Diknas Kota Malang dan dari website setiap sekolah.

4. Data Sekolah SMA dan SMA negeri yang digunakan dalam system informasi geografis ini yaitu SMA dan SMK negeri, akreditasi, jurusan, kelas, kecamatan, alamat, website.

5. Target pengguna yaitu instansi Diknas Pendidikan atau sekolah SMA/SMK Negeri.

6. Data peta hanya mencakup daerah kecamatan lowokwaru, klojen, blimbing, sukun dan kedungkandang.

7. Bahasa pemrograman yang digunakan adalah HTML, PHP, CSS Bootstrap.

\subsection{Manfaat}

Terdapat beberapa manfaat dari pembuatan aplikasi ini sebagai berikut :

1. Dapat menambah pengetahuan dan pengalaman dalam pembuatan sistem informasi geografis sekolah di kota malang.

2. Memberikan sumbangan penelitian untuk dikaji ulang ilmu yang berkaitan dengan pendidikan SMA/SMK pada masyarakat umum.

\section{TINJAUAN PUSTAKA}

\subsection{Penelitian Terdahulu}

Penelitian yang berkaitan dengan Sistem Informasi Geografis Pemetaan Sekolah telah banyak dilakukan dan ditulis oleh para peneliti diantaranya oleh Sasrimita mengenai "Sistem Informasi Geografis Pemetaan Sekolah Di Kecamatan Tanjung Batu Berbasis Mobile". Masalah yang diangkat mengenai Cabang Dinas Pendidikan Tanjung Batu membutuhkan data-data sekolah yang biasanya dikirim secara berkala setiap bulan oleh pihak sekolah, pada akhir bulan data tersebut dijadikan laporan tahunan oleh Dinas Pendidikan. [1]

Kemudian Penelitian yang dilakukan Moh. Aghus Husaini dan Wahyu Dwi P mengenai "Sistem Informasi Geografis (SIG) Pemetaan Sekolah Berbasis Web di Kecamatan Wonodadi Kabupaten
Blitar". Penelitian ini membuat sistem informasi geografis pemetaan sekolah berbasis web agar memudahkan proses pencarian data dan penanganan pendidikan tingkat dasar, menengah pertama dan menengah atas di Kecamatan Wonodadi Kabupaten Blitar. [2]

Pada penelitian ini penulis mengangkat masalah ingin membantu sekolah dan UPT Dinas Pendidikan Kecamatan Padang Utara dalam menyampaikan informasi sekolah yang akan menampilkan letak sekolah beserta informasi secara detail mengenai lokasi sekolah agar lebih mudah melihat sekolah mana saja yang informasi pendidikannya masih kurang, sehingga Dinas Pendidikan dapat memberikan perhatian lebih pada sekolah yang masih kurang sarana dan prasarana pendidikannya. [3]

Selanjutnya penelitian yang di lakukan sebelumnya oleh Lazuardi Yudha Pradana dan Setiawan Assegaff meneliti tentang "Analisis dan Perancangan Sistem Informasi Geografis Pemetaan Sekolah di Kabupaten Tanjung Jabung Barat". Dibutuhkan suatu sistem informasi yang mampu membantu dinas pendidikan terkait dalam menyediakan sarana informasi geografis pemetaan Sekolah bagi masyarakat Kabupaten Tanjung Jabung Barat. [4]

\subsection{Sistem Informasi Geografis}

Sistem Informasi Geografis (SIG) merupakan teknologi yang saat ini menjadi alat membantu (tools) yang sangat esensial dalam menyimpan, memanipulasi, menganalisis dan menampilkan kembali kondisi-kondisi alam dengan bantuan data atribut dan data spasial yang dapat divusualisasikan. [5]

\subsection{Sekolah}

Menurut Daryanto (1997), sekolah adalah bangunan atau lembaga untuk belajar serta tempat menerima dan memberi pelajaran. Jadi, sekolah sebagai suatu sistem sosial dibatasi oleh sekumpulan elemen kegiatan yang berinteraksi dan membentuk suatu kesatuan sosial sekolah yang demikian bersifat aktif kreatif artinya sekolah dapat menghasilkan sesuatu yang bermanfaat bagi masyarakat dalam hal ini adalah orang-orang yang terdidik.2013. [6]

\subsection{Kondisi Geografis Kota Malang}

Kota Malang yang terletak pada ketinggian antara 440 - 667 meter diatas permukaan air laut, merupakan salah satu kota tujuan wisata di Jawa Timur karena potensi alam dan iklim yang dimiliki. Letaknya yang berada ditengah-tengah wilayah Kabupaten Malang secara astronomis terletak $112,06^{\circ}$ - 112,07 ${ }^{\circ}$ Bujur Timur dan 7,06 $-8,02^{\circ}$ Lintang Selatan, dengan batas wilayah. Peta Kota Malang dapat dilihat pada Gambar 1 dibawah setiap kecamatan ditunjukkan dengan perbedaan warna. 


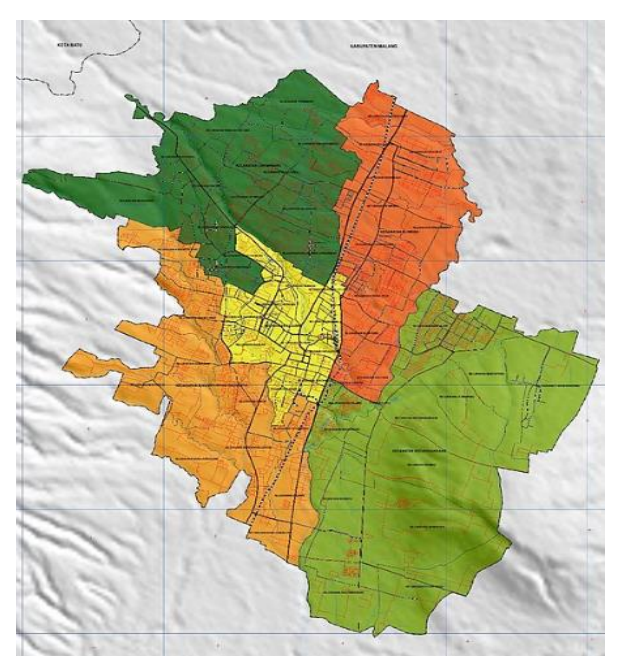

Gambar 1 Peta Kota Malang

\subsection{Software Arcgis}

Arcgis merupakan salah satu perangkat lunak dekstop Sistem Informasi Geografis dan pemetaan yang telah dikembangkan oleh ESRI. Dengan ArcGis, dapat memiliki kemampuan untuk melakukan visualisasi, meng-explore, menjawab query (basis data spasial), menganalisis data secara geografis.

Sistem informasi ini menyediakan wadah untuk pembuatan peta digital dan informasi geografis yang tersedia di organisasi, lintas komunitas, dan secara terbuka di Web. ArcGIS terdiri dari perangkat lunak desktop Windows berikut: [7]

1. ArcReader, yang memungkinkan seseorang untuk melihat dan meminta peta yang dibuat dengan produk ArcGIS lainnya.

2. ArcGIS Desktop (sering disebut sebagai "ArcMap" untuk membedakannya dari ArcGIS Pro), terdiri dari empat aplikasi mendasar sebagai berikut:

a. ArcMap, untuk melihat dan mengedit data spasial dalam dua dimensi dan membuat peta dua dimensi.

b. ArcScene, untuk melihat dan mengedit data spasial tiga dimensi dalam tampilan proyeksi lokal.

c. ArcGlobe, untuk menampilkan dataset 3D global yang besar.

d. ArcCatalog, untuk tugas manajemen data dan manipulasi GIS.

\section{METODE PENELITIAN}

\subsection{Analisis Sistem}

Sistem yang akan dibangun pada sistem informasi geografis pemetaan sekolah SMA/SMK di Kota Malang merupakan sistem untuk menginformasikan sekolah SMA dan SMK serta menginformasikan jumlah PPDB setiap sekolah berbentuk grafik. Sehingga untuk dibangunnya sistem ini, dibutuhkan data-data serta informasi sekolah SMA dan SMK Negeri.

\subsection{Desain Arsitektur Sistem}

Dalam Sistem Informasi Geografis Pemetaan Sekolah SMA/SMK di Kota Malang, dilakukan pemetaaan daerah berdasarkan Kecamatan dari Kota Malang, Terlihat pada Gambar 2

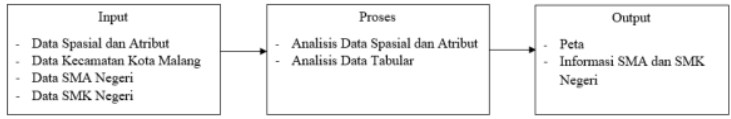

Gambar 2 Desain Arsitektur Sistem

\subsection{Flowchart SIG}

Berikut merupakan flowchart SIG dari sistem informasi geografis pemetaan sekolah SMA/SMK di Kota Malang yang telah di buat pada Gambar 3.

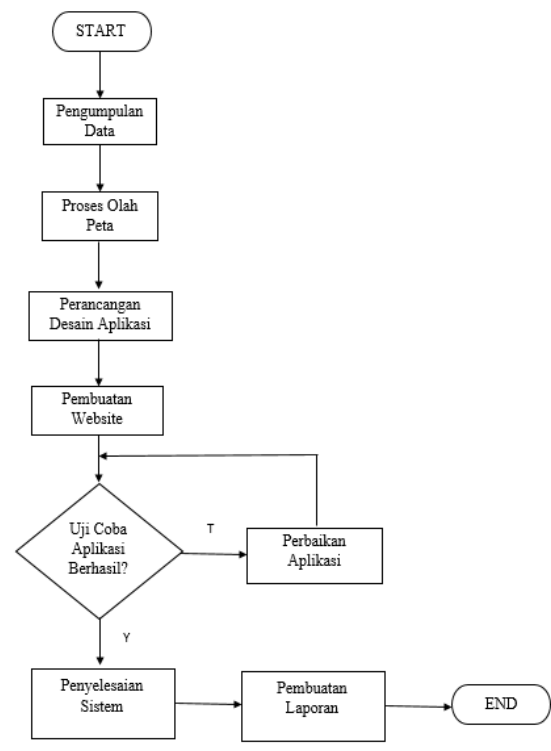

Gambar 3 Flowchart SIG

\subsection{Perancangan Database}

1. Tabel Admin

Tabel admin merupakan tabel yang digunakan untuk menyimpan data admin. Tabel admin ditunjukkan pada tabel 1.

Tabel 1 Struktur Tabel Admin

\begin{tabular}{|c|c|c|}
\hline No & Name & Type \\
\hline 1 & Username & Varchar (50) \\
\hline 2 & Password & Varchar (20) \\
\hline
\end{tabular}

\section{Tabel Data SMA}

Tabel ini berfungsi untuk menyimpan data atribut SMA dan informasi sekolah SMA Negeri yang ada pada Kota Malang. Deskripsi tabel dapat dilihat pada Tabel 2. 
Tabel 2 Struktur Tabel SMA

\begin{tabular}{|c|l|l|}
\hline No & \multicolumn{1}{|c|}{ Name } & \multicolumn{1}{c|}{ Type } \\
\hline 1 & No & Int (10) \\
\hline 2 & SMA & Varchar (50) \\
\hline 3 & Akreditasi & Varchar (10) \\
\hline 4 & Jurusan & Varchar (50) \\
\hline 5 & Kelas & Int (10) \\
\hline 6 & Kecamatan & Varchar (50) \\
\hline 7 & Alamat & Varchar (50) \\
\hline 8 & Website & Varchar (50) \\
\hline
\end{tabular}

3. Tabel Data SMA

Tabel ini berfungsi untuk menyimpan data atribut SMA dan informasi sekolah SMA Negeri yang ada pada Kota Malang. Deskripsi tabel dapat dilihat pada Tabel 3.

Tabel 3 Struktur Tabel Data SMK

\begin{tabular}{|c|l|l|}
\hline No & \multicolumn{1}{|c|}{ Name } & \multicolumn{1}{c|}{ Type } \\
\hline 1 & No & Int (10) \\
\hline 2 & SMK & Varchar (50) \\
\hline 3 & Akreditasi & Varchar (10) \\
\hline 4 & Jurusan & Varchar (200) \\
\hline 5 & Kelas & Int (10) \\
\hline 6 & Kecamatan & Varchar (50) \\
\hline 7 & Alamat & Varchar (100) \\
\hline 8 & Website & Varchar (50) \\
\hline
\end{tabular}

\section{HASIL DAN PEMBAHASAN}

\subsection{Halaman Home}

Halaman home yang diakses oleh user sehingga tidak perlu melakukan login. Halaman ini menampilkan halaman utama pada website sistem informasi geografis sekolah SMA/SMK Kota Malang, Tampilannya seperti Gambar 4.

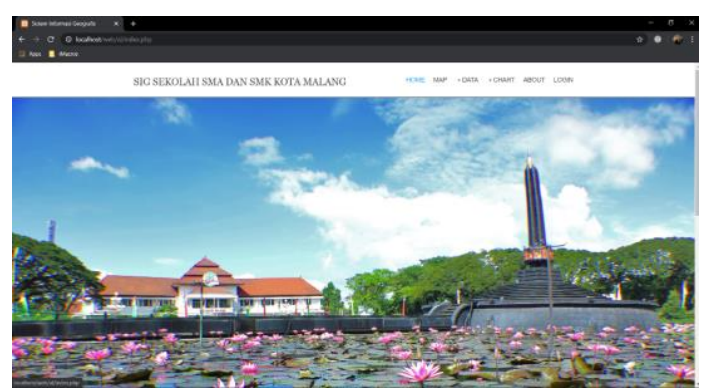

Gambar 4 Halaman Home

\subsection{Halaman Map SMA dan SMK}

Tampilan halaman map, berisikan letak lokasi tiap-tiap sekolah SMA maupun SMK. Tampilan ini juga berisikan informasi yang terdapat pada setiap sekolah, Tampilan seperti Gambar 5.

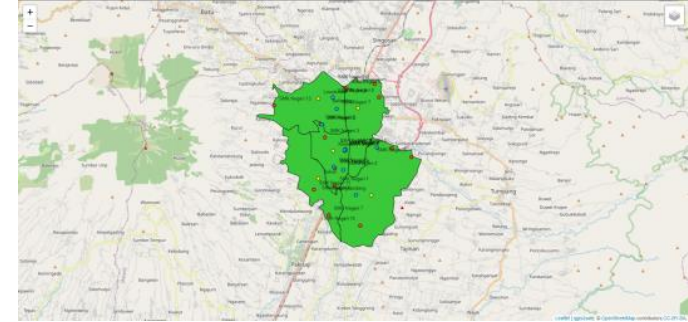

Gambar 5 Halaman Map SMA dan SMK

\subsection{Tampilan Peta Pemetaan SMA Negeri}

Tampilan peta pemetaan SMA Negeri, SMA yang tersebar di beberapa Kecamatan yaitu: Lowokwaru, Klojen dan Kedungkandang. Terdapat pop up informasi singkat sekolah yang ada pada setiap titik sekolah berikut tampilan peta dan informasi pop up pada Gambar 6.

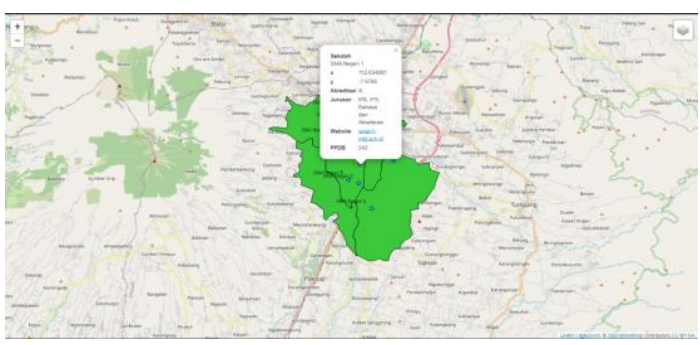

Gambar 6 Tampilan Peta SMA Negeri

\subsection{Tampilan Peta Pemetaan SMK Negeri}

Tampilan peta pemetaan SMA Negeri, SMA yang tersebar di beberapa Kecamatan yaitu: Lowokwaru, Klojen, Blimbing, Sukun, Kedungkandang. Terdapat pop up informasi singkat sekolah yang ada pada setiap titik sekolah berikut tampilan peta dan informasi pop up pada Gambar 7 .

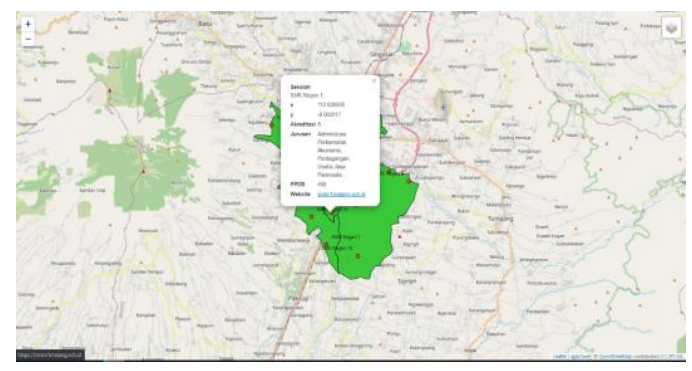

Gambar 7 Tampilan Peta SMK Negeri

\subsection{Tampilan Peta Kuota PPDB SMA Negeri}

Tampilan peta PPDB SMA Negeri, terdapat pop up informasi pada peta yang berisikan jumlah kapasitas penerimaan siswa baru dan jumlah kapasitas penerimaan siswa baru dari luar Kota berikut tampilan pada Gambar 8 . 


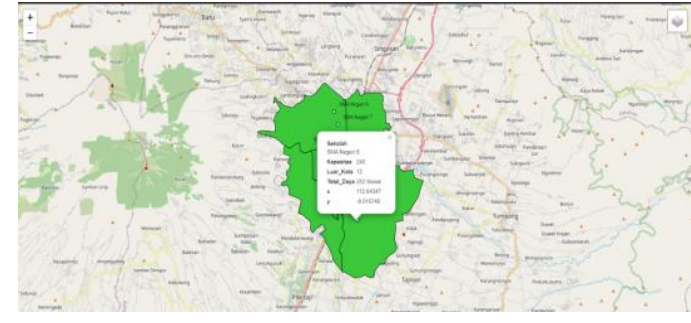

Gambar 8 Tampilan Peta PPDB SMA Negeri

\subsection{Tampilan Peta Kuota PPDB SMK Negeri}

Tampilan peta PPDB SMA Negeri, terdapat pop up informasi pada peta yang berisikan jumlah penerimaan siswa baru pada setiap jurusan dan jumlah kapasitas penerimaan siswa baru dari luar Kota berikut tampilan pada Gambar 9.

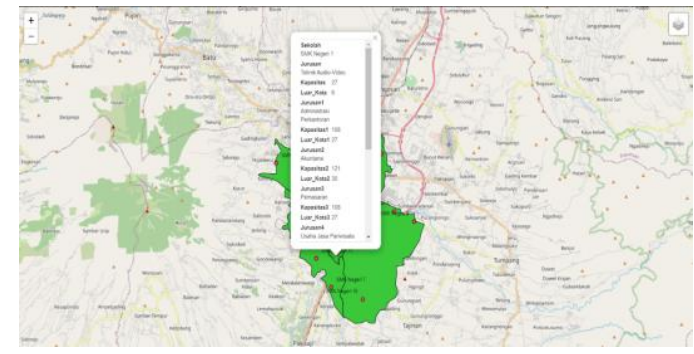

Gambar 9 Tampilan Peta PPDB SMK

\subsection{Halaman Data SMA Negeri}

Halaman data SMA ini berisikan informasi yang lebih lengkap dari tiap-tiap sekolah SMA negeri di Kota Malang, Seperti Gambar 10.

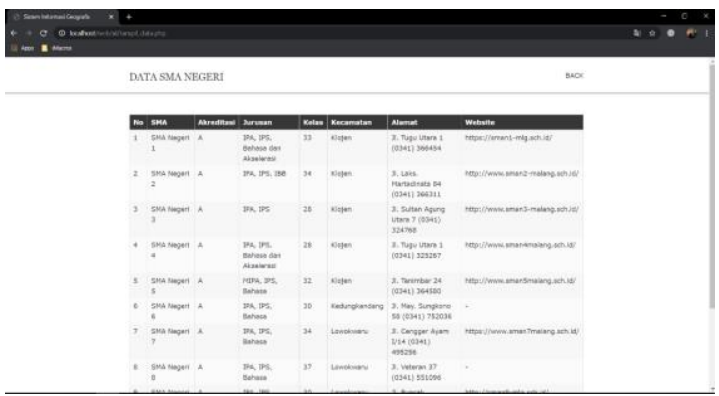

Gambar 10 Halaman Data SMA Negeri

\subsection{Halaman Informasi chart PPDB SMA}

Halaman ini berisikan informasi grafik jumlah penerimaan peserta didik baru di tiap-tiap sekolah SMA negeri di Kota Malang, seperti Gambar 11.
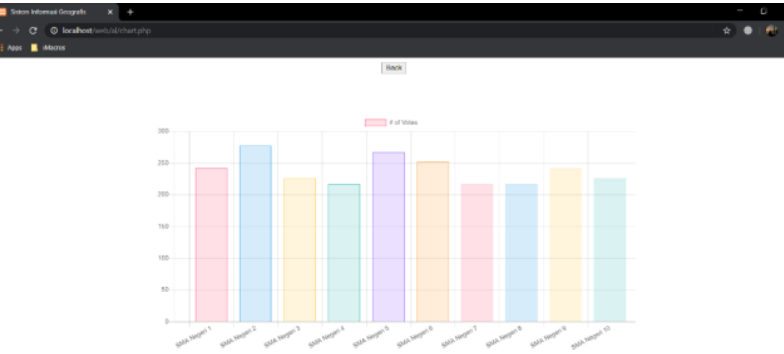

Gambar 11 Chart PPDB SMA

\subsection{Halaman Informasi data SMK Negeri}

Halaman data SMK ini berisikan informasi yang lebih lengkap dari tiap-tiap sekolah SMK negeri di Kota Malang, dapat dilihat ada gambar 12.

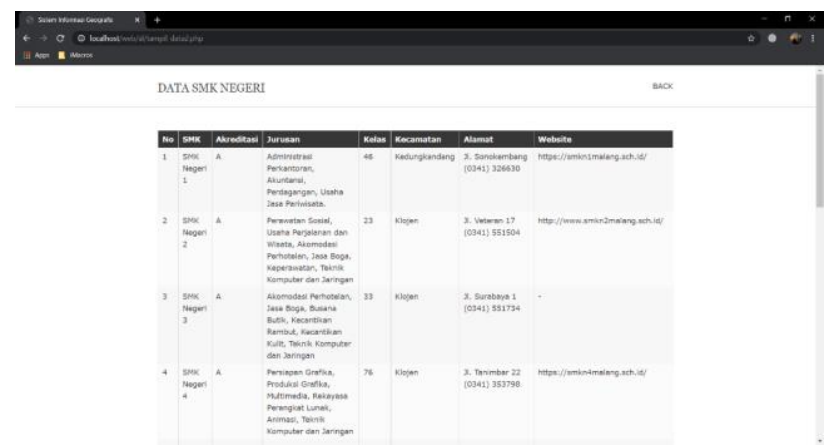

Gambar 12 informasi data SMK Negeri

\subsection{Halaman Informasi chart PPDB SMK}

Halaman ini berisikan informasi grafik jumlah penerimaan peserta didik baru di tiap-tiap sekolah SMK negeri di Kota Malang, seperti Gambar 13.

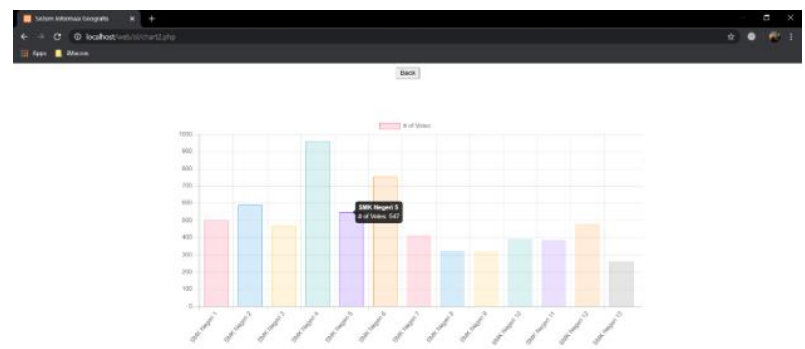

Gambar 13 Chart PPDB SMA

\subsection{Halaman Login Admin}

Halaman login ini untuk admin jika ingin mengubah, menambah dan menghapus data SMA dan SMK. Sebelum masuk ke halaman admin harus login terlebih dahulu pada halaman login, Berikut tampilan login admin pada Gambar 14. 


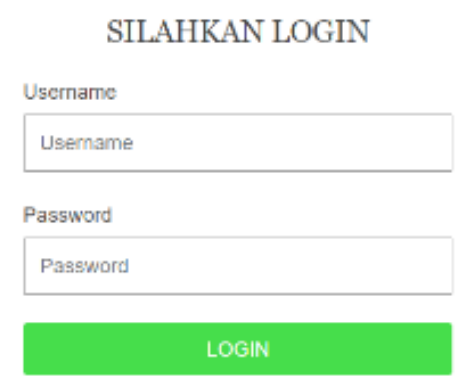

Gambar 14 Halaman login admin

\subsection{Halaman Admin}

Halaman admin yang hanya bisa diakses dengan memasukkan username dan password yang telah dibuat dan proses login berhasil. Halaman ini berisikan tentang data SMA negeri dan SMK Negeri tampilan dapat dilihat pada Gambar 15

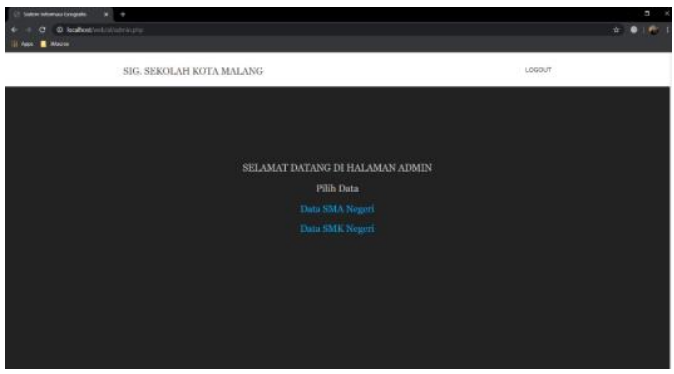

Gambar 15 Halaman admin

\subsection{Halaman data SMA}

Halaman ini berisi daftar data SMA Negeri yang telah dimasukkan oleh admin. Dibagian kanan pada tabel terdapat dua link, admin bisa memilih untuk mengubah dan menghapus data, tampilan dapat dilihat pada Gambar 16.

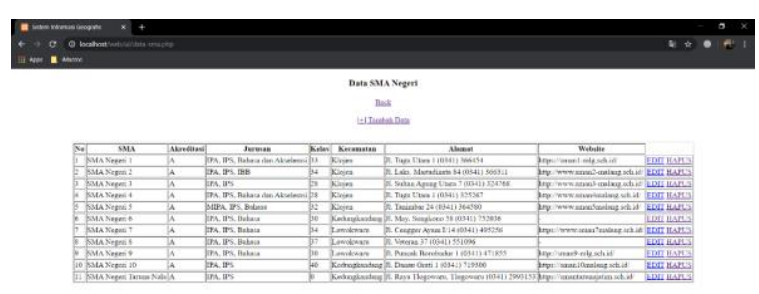

Gambar 16 Tampilan data SMA

\subsection{Halaman tambah data SMA}

Halaman ini berisi form untuk menambah data SMA. Data yang ditambahkan adalah No, SMA, Akreditasi, Jurusan, Kelas, Kecamatan, Alamat, Website. Tampilan dapat dilihat pada Gambar 17.

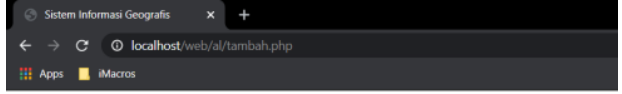

Tambah Data SMA

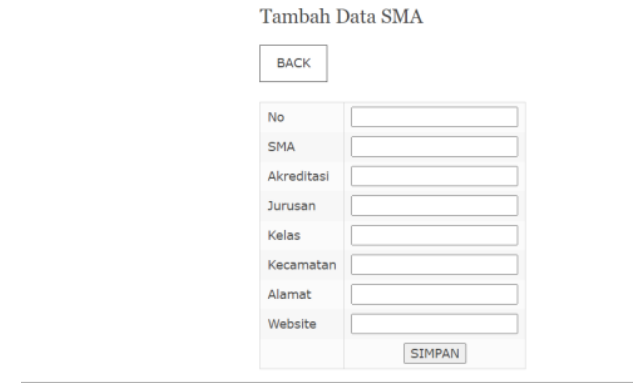

Gambar 17 Halaman Form tambah data

\subsection{Halaman edit data}

Halaman edit data SMA digunakan untuk mengubah data setiap baris pada tabel SMA seperti Gambar 15.

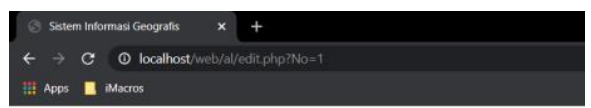

Edit Data Sekolah SMA

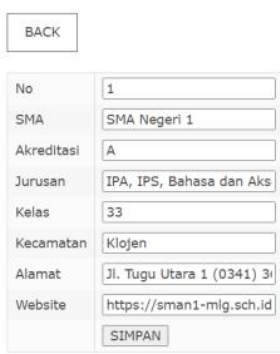

Gambar 18 Tampilan Form Edit data

\subsection{Halaman data SMK}

Halaman ini berisi daftar data SMK Negeri yang telah dimasukkan oleh admin. Dibagian kanan pada tabel terdapat dua link, admin bisa memilih untuk mengubah dan menghapus data, tampilan dapat dilihat pada Gambar 19.

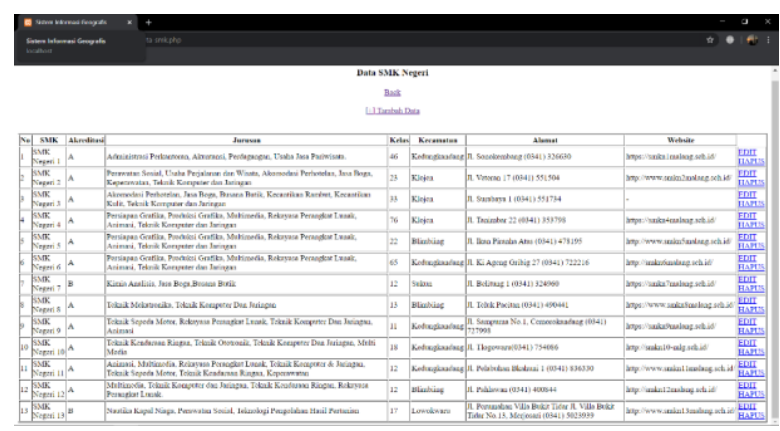

Gambar 19 Tampilan data SMK

\subsection{Halaman tambah data SMK}

Halaman ini berisi form untuk menambah data SMK. Data yang ditambahkan adalah No, SMK, 
Akreditasi, Jurusan, Kelas, Kecamatan, Alamat, Website. Tampilan dapat dilihat pada Gambar 20.

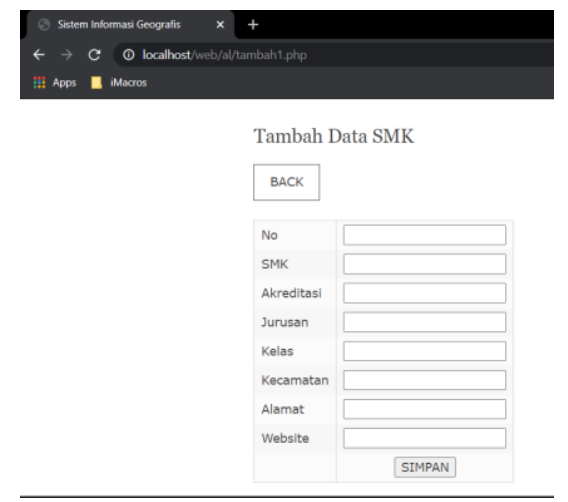

Gambar 20 Halaman Form tambah data

\subsection{Halaman edit data}

Halaman edit data SMK digunakan untuk mengubah data setiap baris pada tabel SMK seperti Gambar 21.

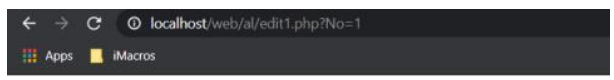

Edit Data Sekolah SMK

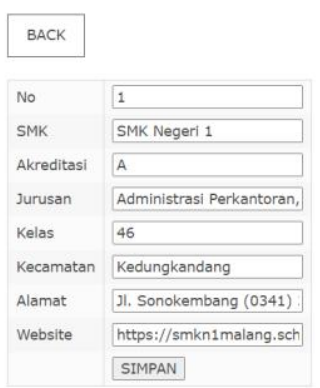

Gambar 22 Halaman form edit data

\subsection{Halaman about}

Halaman ini berisi informasi pembuat aplikasi, tampilan halaman about dapat dilihat pada Gambar 23.

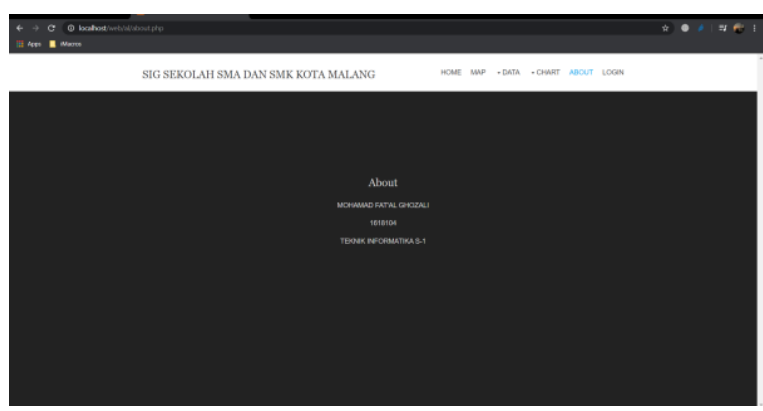

Gambar 23 Halaman about

\subsection{Pengujian Fungsional Sistem}

Pengujian sistem merupakan proses menampilkan sistem dengan maksud untuk menemukan adanya kesalahan atau tidak pada sistem sebelum sistem dipublikasikan untuk digunakan oleh masyarakat. Hasil pengujian sistem ditunjuakkan pada Tabel 4 sebagai berikut.

Tabel 4 Pengujian Fungsional

\begin{tabular}{|c|l|c|c|c|}
\hline \multirow{2}{*}{ No } & \multirow{2}{*}{$\begin{array}{l}\text { Item Yang } \\
\text { Di Uji }\end{array}$} & \multicolumn{3}{|c|}{ Nama Browser } \\
\cline { 3 - 5 } & \multicolumn{1}{|c|}{$\begin{array}{c}\text { Google } \\
\text { Chrome }\end{array}$} & $\begin{array}{c}\text { Microsoft } \\
\text { Edge }\end{array}$ & $\begin{array}{c}\text { Mozila } \\
\text { Firefox }\end{array}$ \\
\hline 1 & $\begin{array}{l}\text { Halaman } \\
\text { Utama } \\
\text { Website }\end{array}$ & $\checkmark$ & $\checkmark$ & $\checkmark$ \\
\hline 2 & $\begin{array}{l}\text { Halaman Peta } \\
\text { Website }\end{array}$ & $\checkmark$ & $\checkmark$ & $\checkmark$ \\
\hline 3 & $\begin{array}{l}\text { Halaman } \\
\text { Data SMA }\end{array}$ & $\checkmark$ & $\checkmark$ & $\checkmark$ \\
\hline 4 & $\begin{array}{l}\text { Halaman } \\
\text { Data SMK }\end{array}$ & $\checkmark$ & $\checkmark$ & $\checkmark$ \\
\hline 5 & $\begin{array}{l}\text { Halaman } \\
\text { Tampilan } \\
\text { Chart PPDB }\end{array}$ & $\checkmark$ & $\checkmark$ & $\checkmark$ \\
\hline 6 & $\begin{array}{l}\text { Halaman } \\
\text { Admin }\end{array}$ & $\checkmark$ & $\checkmark$ & $\checkmark$ \\
\hline 7 & $\begin{array}{l}\text { Halaman } \\
\text { About }\end{array}$ & $\checkmark$ & $\checkmark$ & $\checkmark$ \\
\hline
\end{tabular}

Keterangan :

$\sqrt{ }=$ Berjalan

$\mathrm{x}=$ Tidak Berjalan

Versi Browser :

Mozila Firefox : 70.0.1(32-bit)

Google Chrome : 78.0(64-bit)

Microsoft Edge : 11.0.7(64-bit)

\subsection{Pengujian Black Box}

Rencana pengujian yang akan dilakuhkan dengan menguji sistem menggunakan metode blackbox. Pengujian Black-Box pada Tabel 5.

Tabel 5 Pengujian Black-Box

\begin{tabular}{|l|l|l|l|l|}
\hline No & Butir uji & $\begin{array}{l}\text { Hasil yang } \\
\text { diharapkan }\end{array}$ & $\begin{array}{c}\text { Hasil } \\
\text { sebenarnya }\end{array}$ & Hasil \\
\hline 1 & $\begin{array}{l}\text { Login } \\
\text { Admin }\end{array}$ & $\begin{array}{l}\text { Data mengisi } \\
\text { datogin, } \\
\text { verifikasi } \\
\text { username dan } \\
\text { password }\end{array}$ & $\begin{array}{l}\text { Verifikasi } \\
\text { username } \\
\text { dan } \\
\text { password }\end{array}$ & Sesuai \\
\hline
\end{tabular}




\begin{tabular}{|c|c|c|c|c|}
\hline 2 & $\begin{array}{l}\text { Halaman } \\
\text { admin }\end{array}$ & $\begin{array}{l}\text { Dapat masuk } \\
\text { ke halaman } \\
\text { admin }\end{array}$ & $\begin{array}{l}\text { Masuk ke } \\
\text { halaman } \\
\text { admin dan } \\
\text { terdapat } \\
\text { menu } \\
\text { pilihan data } \\
\text { SMA } \\
\text { Negeri dan } \\
\text { data SMK } \\
\text { Negeri }\end{array}$ & Sesuai \\
\hline 3 & $\begin{array}{l}\text { Halaman } \\
\text { data } \\
\text { SMA } \\
\text { Negeri } \\
\text { admin } \\
\end{array}$ & $\begin{array}{l}\text { Data yang } \\
\text { telah di } \\
\text { inputkan pada } \\
\text { database SMA } \\
\text { Negeri }\end{array}$ & $\begin{array}{l}\text { Data tampil } \\
\text { pada } \\
\text { halaman } \\
\text { data SMA } \\
\text { Negeri } \\
\end{array}$ & Sesuai \\
\hline 4 & $\begin{array}{l}\text { Halaman } \\
\text { tambah } \\
\text { data } \\
\text { SMA } \\
\text { Negeri }\end{array}$ & $\begin{array}{l}\text { Proses } \\
\text { memasukkan } \\
\text { data SMA } \\
\text { yang baru } \\
\text { dapat } \\
\text { tersimpan di } \\
\text { database }\end{array}$ & $\begin{array}{l}\text { Data } \\
\text { berhasil di } \\
\text { simpan di } \\
\text { database }\end{array}$ & Sesuai \\
\hline 5 & $\begin{array}{l}\text { Halaman } \\
\text { edit data } \\
\text { SMA } \\
\text { Negeri }\end{array}$ & $\begin{array}{l}\text { Mengubah } \\
\text { data SMA } \\
\text { yang sudah } \\
\text { ada di dalam } \\
\text { database }\end{array}$ & $\begin{array}{l}\text { Proses } \\
\text { perubahan } \\
\text { data } \\
\text { berhasil }\end{array}$ & Sesuai \\
\hline 6 & $\begin{array}{l}\text { Halaman } \\
\text { hapus } \\
\text { data } \\
\text { SMA } \\
\text { Negeri } \\
\end{array}$ & $\begin{array}{l}\text { Menghapus } \\
\text { data SMA di } \\
\text { dalam } \\
\text { database }\end{array}$ & $\begin{array}{l}\text { Proses } \\
\text { hapus data } \\
\text { berhasil }\end{array}$ & Sesuai \\
\hline 7 & $\begin{array}{l}\text { Halaman } \\
\text { data } \\
\text { SMK } \\
\text { Negeri } \\
\text { admin }\end{array}$ & $\begin{array}{l}\text { Data yang } \\
\text { telah di } \\
\text { inputkan pada } \\
\text { database SMK } \\
\text { Negeri }\end{array}$ & $\begin{array}{l}\text { Data tampil } \\
\text { pada } \\
\text { halaman } \\
\text { data SMK } \\
\text { Negeri }\end{array}$ & Sesuai \\
\hline 8 & $\begin{array}{l}\text { Halaman } \\
\text { tambah } \\
\text { data } \\
\text { SMK } \\
\text { Negeri }\end{array}$ & $\begin{array}{l}\text { Proses } \\
\text { memasukkan } \\
\text { data SMK } \\
\text { yang baru } \\
\text { dapat } \\
\text { tersimpan di } \\
\text { database } \\
\end{array}$ & $\begin{array}{l}\text { Data } \\
\text { berhasil di } \\
\text { simpan di } \\
\text { database }\end{array}$ & Sesuai \\
\hline 9 & $\begin{array}{l}\text { Halaman } \\
\text { edit data } \\
\text { SMK } \\
\text { Negeri }\end{array}$ & $\begin{array}{l}\text { Mengubah } \\
\text { data SMK } \\
\text { yang sudah } \\
\text { ada di dalam } \\
\text { database } \\
\end{array}$ & $\begin{array}{l}\text { Proses } \\
\text { perubahan } \\
\text { data } \\
\text { berhasil }\end{array}$ & Sesuai \\
\hline 10 & $\begin{array}{l}\text { Halaman } \\
\text { hapus } \\
\text { data } \\
\text { SMK } \\
\text { Negeri }\end{array}$ & $\begin{array}{l}\text { Menghapus } \\
\text { data SMK di } \\
\text { dalam } \\
\text { database }\end{array}$ & $\begin{array}{l}\text { Proses } \\
\text { hapus data } \\
\text { berhasil }\end{array}$ & Sesuai \\
\hline
\end{tabular}

\section{KESIMPULAN DAN SARAN}

\subsection{Kesimpulan}

Berdasarkan hasil dari perancangan dan implementasi dari aplikasi Pemanfaatan Sistem Informasi Geografis untuk Pemetaan Sekolah SMA/SMK di Kota Malang berbasis website maka dapat diambil beberapa kesimpulan yaitu:

1. Berdasarkan hasil dari pengujian pembangunan Sistem Informasi Geografis dengan menggunakan ArcGis 10.7 telah lakukan, dapat di buktikan dengan aplikasi sistem informasi geografis pemetaan sekolah SMA/SMK di Kota Malang sudah mampu memberikan informasi diantaranya informasi sekolah SMA, SMK, akreditasi, jurusan, jumlah kelas dan website sekolah.

2. Berdasarkan hasil dari penelitian maka aplikasi Sistem Informasi Geografis untuk Pemetaan Sekolah SMA/SMK di Kota Malang Berbasis WEB ini dapat disajikan dalam bentuk Website dan dapat menampilkan informasi dari setiap sekolah, menampilkan peta dan menampilkan grafik penerimaan siswa baru, hal tersebut bertujuan untuk memudahkan masyarakat dan Diknas pendidikan untuk mendapatkan informasi melalui website.

3. Berdasarkan hasil pengujian fungsional aplikasi Sistem Informasi Geografis untuk Pemetaan Sekolah SMA/SMK di Kota Malang berjalan sesuai dengan apa yang di harapkan, yakni dapat dijalankan pada browser mozila firefox, google chrome dan Microsoft edge.

\subsection{Saran}

Agar dalam aplikasi ini berjalan dengan baik kedepannya, maka ada beberapa hal yang perlu dilakukan yaitu sebagai berikut:

3. Sistem Informasi Geografis untuk Pemetaan Sekolah SMA/SMK di Kota Malang dapat dikembangkan lagi agar menjadi lebih baik. Caranya dengan menambahkan dalam bentuk aplikasi android agar memudahkan pengguna smartphone langsung mengakses tanpa bantuan aplikasi browser.

4. Pengembangan aplikasi Sistem Informasi Geografis untuk Pemetaan Sekolah SMA/SMK data yang ada masih belum cukup lengkap agar ditambahkan data yang lebih lengkap.

\section{DAFTAR PUSTAKA}

[1] Sasrimita, S. (2016). SISTEM INFORMASI GEOGRAFIS PEMETAAN SEKOLAH DI KECAMATAAN TANJUNG BATU BERBASIS MOBILE.(Skripsi) (Doctoral dissertation, UIN Raden Fatah Palembang).

[2] Husaini, M. A. (2017). Sistem Informasi Geografis (SIG) Pemetaan Sekolah Berbasis Web DI Kecamatan Wonodadi Kabupaten Blitar. ANTIVIRUS: Jurnal Ilmiah Teknik Informatika, 11(1)

[3] Nelfira, A., \& Putra, A. W. Y. (2018). SISTEM INFORMASI GEOGRAFIS PEMETAAN SEKOLAH (SCHOOL MAPPING) BERBASIS WEB GIS PADA UPT DINAS PENDIDIKAN KECAMATAN PADANG UTARA. Menara Ilmu, $\quad$ 12(11).

[4] Pradana, L. Y., \& Assegaff, S. (2019). ANALISIS DAN PERANCANGAN SISTEM INFORMASI GEOGRAFIS PEMETAAN 
SEKOLAH DI KABUPATEN TANJUNG JABUNG BARAT. Jurnal Manajemen Sistem Informasi, 4(1), 38-47.

[5] Arfiani, I. (2012). Sistem Informasi Geografis Untuk Pemetaan Dan Pencarian Rumah Sakit Di
Kota Yogyakarta. Jurnal Informatika Ahmad Dahlan, 6(2), 103109.

[6] Daryanto, S. S. (1997). Kamus bahasa Indonesia lengkap. Surabaya: Apollo, 122, 123.

[7] Wikipedia 20 February 2020. <https:// https://en.wikipedia.org/wiki/ArcGIS/> 